Article title: Towards Defining the Place and Role of Robotics MOOCs in ODeL

Authors: Patricia Gouws[1], Hugo Lotriet[2], Mukondeleli Grace Kanakana-Katumba[3], Denzil Chetty[4]

Affiliations: School of Computing, College of Science, Engineering and Technology, University of South Africa[1], Tshwane University of Technology[2], Department of Tuition Support and Facilitation of Learning, University of South Africa[3]

Orcid ids: 0000-0001-9820-8544[1], 0000-0002-0353-5073[2], 0000-0001-7475-2131[3], 0000-0002-4749-8788[4]

Contact e-mail: lotrihh@unisa.ac.za

License information: This work has been published open access under Creative Commons Attribution License http://creativecommons.org/licenses/by/4.0/, which permits unrestricted use, distribution, and reproduction in any medium, provided the original work is properly cited. Conditions, terms of use and publishing policy can be found at https://www.scienceopen.com/.

Preprint statement: This article is a preprint and has not been peer-reviewed, under consideration and submitted to UnisaRxiv for open peer review.

Funder: N/A

DOI: $10.25159 /$ UnisaRxiv/000017.v1

Preprint first posted online: 31 May 2021

Keywords: MOOC, robotics education, science engagement, STEM 


\section{Towards Defining the Place and Role of Robotics MOOCs in ODeL}

Patricia M. Gouws

https://orcid.org/0000-0001-9820-8544

College of Science, Engineering and

Technology, University of South

Africa

Mukondeleli G. Kanakana-Katumba

https://orcid.org/0000-0001-7475-2131

Tshwane University of Technology,

South Africa
Hugo Lotriet

https://orcid.org/0000-0002-0353-5073

College of Science, Engineering and

Technology, University of South

Africa

lotrihh@unisa.ac.za

\section{Denzil Chetty}

https://orcid.org/0000-0002-4749-8788

Department of Tuition Support and

Facilitation of Learning, University of

South Africa

\section{Abstract}

This paper focuses on the limited literature pertaining to robotics MOOCs within the STEM MOOC domain. This study provides a subset of an ongoing, more extensive systematic review of the recent advances with MOOCs to advance STEM education and engagement. The purpose of this study is to identify and discuss the place and role of robotics (as a subset of STEM) MOOCs in an open distance e-learning institution of higher education. The study provides insights into the research gaps existing in (1) literature, and (2) the domain of STEM MOOCs for robotics education and STEM engagement. The place and role of STEM MOOCs for the advancement of robotics within an open distance e-learning institution provide a practical and sustainable solution to science engagement in these times of Covid.

Keywords: STEM, MOOC, robotics education, science engagement

\section{Introduction}

Robotics is a major disruptor within the context of the Fourth Industrial Revolution (4IR) (Schwab 2017). Robotics education has long been an effective entry point for tuition and learning related to Science, Technology, Engineering, and Mathematics (STEMM) (Johnson 2003) and thus has significant potential to interest learners in career paths in computing-related areas (Beyers and Van der Merwe 2017) and to provide learners with the skills required to benefit from the economic advantages associated with the 4IR. However, competent digitally skilled (robotics) coaches (educators, mentors and community leaders) are essential for the achievement of this ideal (see Alimisis 2019). 
As members of a community of coaches, robotics coaches require access to robotics training to be equipped, to be mentored and to be empowered in robotics (an example of this can be found in Shannon 2015). The confident and competent core of robotics coaches, in turn, will train and educate the learners in robotics. The robotics coaches require access to robotics training and equipping, access to other like-minded coaches, access to robotics resources to deal with the challenges of time and distance constraints to attend robotics training, and (in these times) access to the resources to deal with the additional challenge of the Covid-19 constraints.

Inspired towards Science, Engineering and Technology (I-SET) is a community science engagement flagship project of the College of Science, Engineering and Technology at Unisa, an open distance e-learning (ODeL) institution of higher education. The I-SET project has already deployed a range of opportunities for equipping and empowering coaches and their robotics teams of learners in robotics education for more than a decade (since June 2009). However, the increasing and urgent national demand for robotics education for all learners is hindered by access, time, distance, commitment, and funding constraints. These challenges have been exacerbated by austerity measures (thus trimmed budgets) of higher education institutions where budget cuts were implemented for all community engagement projects. This has been worsened by Covid-19 constraints, where travel has been halted, funding has been limited, and faceto-face workshops and expos have been cancelled.

The austerity measures implemented within the community engagement projects of Unisa, the ODeL institution, necessitated that the I-SET project team explore and experiment with alternative implementation opportunities for robotics engaging, equipping, and training. One such opportunity presented was developing and using STEM massive open online courses (MOOCs) on the Unisa open learning portal, specifically robotics for science engagement. Since the implementation of Covid regulations, these robotics STEM MOOCs have been enhanced and supplemented by regular online meetings (on Microsoft Teams) with (online) engagement communities to further equip and empower robotics coaches. The schedule for these I-SET robotics live online learning sessions is revised and published each month.

Given the current Covid pandemic and the lack of science engagement within the realm of face-to-face robotics workshops of the I-SET project at Unisa, MOOCs thus provide a potentially viable solution for providing access and equipping a community of coaches. This is currently the role and place of robotics MOOCs in ODeL. As MOOCs currently are the only point of access for the I-SET robotics engagement, the need arose to ensure that the development and implementation of these MOOCs are understood in a good scholarly way, and that lessons that could be learned from scholarly papers on MOOCs are considered. Conversely, the question arose on the potential contribution to the scholarship of tuition and learning in STEM MOOCs from research on the I-SET MOOCs. 
To align the development and implementation of these STEM MOOCs in robotics with current literature and to understand the current state of knowledge about STEM MOOCs (including robotics MOOCs), a systematic literature review ${ }^{1}$ of STEM MOOCs was therefore initiated ongoing into the foreseeable future. This paper presents the details of a subset of the reviewed literature, specifically relevant to the teaching and learning of robotics. However, the multidisciplinary domain of robotics also includes the subject domains of programming, engineering, and physics. These three knowledge domains were therefore also included in the current focused study. For a complete initial overview of the state of research on STEM MOOCs see Gouws, Lotriet, and Katumba (2021).

\section{Literature}

The literature included in the systematic literature review focused on STEM MOOCs specifically, categorised into the specific subject domains STEM (including robotics, physics, engineering, and programming). The purpose of this study is to understand the role and place of STEM MOOCs, specifically for robotics, in an ODeL environment.

\section{Robotics Education and Educational Robotics}

Robotics education is the teaching and learning of the knowledge domain of robotics. Robotics education provides impactful learning in formal and informal learning settings (Anwar et al. 2019). Several themes were identified in a systematic review of educational robotics research (Anwar et al. 2019). While the learner benefits of learning effectiveness, twenty-first century skills development, creativity, and motivation were highlighted, the need for (ongoing) professional development is outlined. Educators need to be supported and equipped with the skills to include robotics in their teaching in terms of both content and pedagogy. It is mentioned that MOOCs have been deployed to increase the educator effectiveness in robotics.

\section{Resources and Access to Robotics Resources}

The resources for the teaching and learning of robotics to develop robotics education need to accessible to all, especially to the educators who are developing the learner skills of robotics. Although a plethora of online educational resources is investigated and presented, it is noted that the demand for online resources has increased in these times of Covid-19. However, it is also noted that the use of these online resources is underutilised. Although extensive collections of random-access resources are available, guided access to relevant and quality resources is required. Educators are already

1 An initial report on the systematic review on STEM MOOC education was presented at the 2021 STEMI COP conference (Gouws, Lotriet, and Katumba 2021). 
constrained by time and need access to appropriate resources (Pozzi, Prattichizzo, and Malvezzi 2021). It is noted that an experience within a robotics MOOC will encourage motivation and autonomous learning (Canonne et al. 2015).

Robotics is interdisciplinary; thus, resources need to include programming, physics, and engineering. A categorisation of online resources is proposed in terms of explanation, inspiration, and practical resources. Several online robotics courses that focus on robotics foundations, robotics advanced, robot building and programming, and the impact of robotics on society are included in the list (Pozzi, Prattichizzo, and Malvezzi 2021), and an online robotics course for primary school learners is explored (Pisarov and Mester 2019).

\section{MOOCs}

As noted in the name, MOOCs are "massive," "open" and "online". MOOCs are structured courses that are designed for scalability. MOOCs create space for guided learning, assessment, mentoring and access to additional resources. The resources for the teaching and learning of robotics and related fields must be included in MOOCs to ensure access. The target audience, in general, is the public, where no prerequisite knowledge is required. However, MOOCs can also be developed as educational opportunities for a focused audience, for example educators. For the study, it was recommended that a single institution of higher education be analysed for communication and administrative purposes (Tømte 2019).

\section{MOOCS and Access to Robotics Education}

The use of online resources for the promotion of robotic education is presented. Although several robotics MOOCs are listed in the article, there is limited research pertaining to these robotics MOOCs specifically. Robotics MOOCs for undergraduate students (with basic mathematics and physics knowledge) are categorised and listed as single courses or grouped courses, for school learners and educators, for general public, and for specific robotics applications (Pozzi, Prattichizzo, and Malvezzi 2021). It is noted, however, that the MOOC content can also be delivered as online lecture series, YouTube channels or podcasts. Flipping the classroom is used to accommodate both the theoretical and practical aspects of the robotics learning. In these cases, students were required to access the content of the learning from the MOOC and to access the practical learning in a classroom. It is, however, noted that the learning gaps between theory and practice, and between hardware and simulations need to be taken into account (De la Croix and Egerstedt 2014). While the content of the Begin Robotics MOOC was levelled for undergraduates, the purpose of the use of the MOOC was to recruit schools learners into the institute of higher education (Mitchell 2018). 
MOOC research has reported on different levels of resource use owing to the skill levels of the participating students, which in turn have an impact on the MOOC design decisions (Balint et al. 2017). The initial state of students participating in the MOOC also needs to be considered, to inform the community of learning for the ongoing improvement of the MOOC space (Aiken et al. 2014).

Engineering is considered part of the multidisciplinary field of robotics. This consideration for engineering MOOCs may be used as a guide for the development of robotics MOOCs, and also to understand engineering education. The importance of communication and interaction is highlighted (Shailaja and Prathikantham 2018). The negatives (class size and related administrative issues, time required, the fundamental complexity of engineering MOOCs owing to the volume of prerequisite knowledge) were outweighed by the positives (the high levels of demand for engineering content, the theory content presented in MOOC format together with a practical aspect, the large extended reach of learning). A warning is presented that the "democratisation" aspect of MOOC experience should not be understated (De la Croix and Egerstedt 2014).

Programming is also a discipline that is included in robotics. Programming MOOCs are considered in terms of the high drop rates (Gong, Liu, and Zhao 2019). Robotics, as with programming, has limited research that focuses on the emotions of the learning experience. Programming and robotics are both considered challenging learning tasks and experiences.

The robotics content of a MOOC may be presented in a diverse range of formats - i.e. (1) a taught MOOC, which implies instructor led; (2) a self-paced MOOC allowing for the participant to work at their own pace; (3) an instructor-led MOOC, with elements of student support through planned webinars; (4) "open" with no start or end date; or (5) structured as a taught course with a definite start and end date. A robotics competition has been inserted into robotics and embedded systems MOOC (Sahay, Gholkar, and Arya 2019). The engagement with robotics content of a MOOC can be understood and interpreted through the interpretation of the MOOC analytics. This leads to a better understanding of the use of MOOCs, especially STEM MOOCs for school learners (Khalil and Ebner 2015).

In an evaluation report of a robotics MOOC, the design of the MOOC, and the student engagement and motivations are presented and analysed. These combined analytics are evaluated to ensure the ongoing improvement of the MOOC. The data collected were also used to contribute to the learning analytics body of knowledge (Philip and Greener 2016).

From the literature, it was noted that MOOCs are limited to European languages (Pozzi, Prattichizzo, and Malvezzi 2021). This poses a critical research question in terms of the audience for whom the MOOCs are created. It is also noted the rich diversity that needs to be reflected in MOOCs in Africa (Adam 2020). Such analysis reveals potential for 
the Africanising of MOOCs, in terms of language, design and curriculum. Ongoing research elaborated on a proposed strategy for possible MOOC implementations within Africa, as a continent of limited resources (Oyo and Kalema 2020). These research paths contribute to the definition of role and place of MOOCs within an ODeL Unisa, as the Africa university, in service of humanity.

\section{Research Problem}

The research question dealt with in this article is: What is the potential place for STEM robotics MOOCs in support of STEM engagement within an ODeL institution to increase community reach and engagement impact?

\section{Research Methodology - Systematic Literature Review}

Because of the nature of the research question, a systematic literature review was selected as the most appropriate research method. The method that was used consisted of the following steps: (1) determination of the research question; (2) determination of search terms; (3) compilation of inclusion and exclusion criteria; (4) selection of databases to be used; (5) searches conducted; (6) screening of papers on the title and abstract, and full text; and (7) coding of selected full-text papers.

\section{Search Terms Used}

The search terms that were used are shown in Table 1. The search focused on the intersection of three main areas of interest, thus MOOCS, STEM disciplines, and engagement. For this paper, the environmental and agricultural sciences were not part of the present study.

Table 1: The systematic review terms

\begin{tabular}{|c|c|}
\hline Topic String 1 & Search Strings \\
\hline MOOCS & $\begin{array}{l}\text { "MOOC*" OR "Massive Open Online Course" OR "Non-formal } \\
\text { Education" OR "Informal education" }\end{array}$ \\
\hline STEM & $\begin{array}{l}\text { "STEM" OR "science" or "physics" OR "math*” OR } \\
\text { "engineering" OR "chemistry" OR "astronomy" OR "statistics" OR } \\
\text { "programming" OR "computer science" OR "computing" OR } \\
\text { "informatics" OR "robotics" OR "AI" OR "artificial } \\
\text { intelligence" OR "astronomy" } \\
\text { NOT "social science" OR "political science" OR “consumer } \\
\text { science" OR "life science" OR "medical science" OR "animal } \\
\text { science" OR "geography*” OR "biolog*” }\end{array}$ \\
\hline $\begin{array}{l}\text { Learning } \\
\text { engagement }\end{array}$ & $\begin{array}{l}\text { "complet*” OR “attrition" OR “engagement" OR “participat*” OR } \\
\text { "throughput" OR "success" OR “dropout" OR "retention" OR } \\
\text { "experience" }\end{array}$ \\
\hline
\end{tabular}




\section{Inclusion and Exclusion Criteria}

Inclusion and exclusion criteria took into consideration the period of existence of MOOCs (2008 onwards), language, and types of publication. MOOCs only became active in 2008, thus research pertaining to MOOCs only became relevant thereafter. The team thus selected 2008 as a reference year to gather relevant literature for the review. The inclusion and exclusion criteria were used to ensure a level of academic quality assurance in the papers and articles selected for this paper. The inclusion and exclusion criteria used for this systematic review are presented in Table 2 .

Table 2: The inclusion and exclusion criteria

\begin{tabular}{|l|l|}
\hline Include & Exclude \\
\hline Published from 2008 onwards & Published before 2008 \\
\hline English language & Not in English \\
\hline Primary, empirical research & Grey literature \\
\hline Theoretical articles & Reviews \\
\hline Conference papers & \\
\hline Journal papers & \\
\hline
\end{tabular}

\section{Databases Selected}

Databases that were used for the search were Web of Science, Scopus, and ERIC. These three databases were selected because of the educational nature of the research, and the focus on science, engineering, and technology.

\section{Extraction Process}

The steps followed during the extraction process include the searching of the chosen databases using the search strings shown in Table 1; the exporting of the search results into EPPI; the exclusion of duplicate articles; the screening of titles and abstracts for relevance; the uploading of the full papers; the screening on the full papers; the further exclusions; the coding of the papers; and the querying of the codes. The process is set out in Figure 1. 


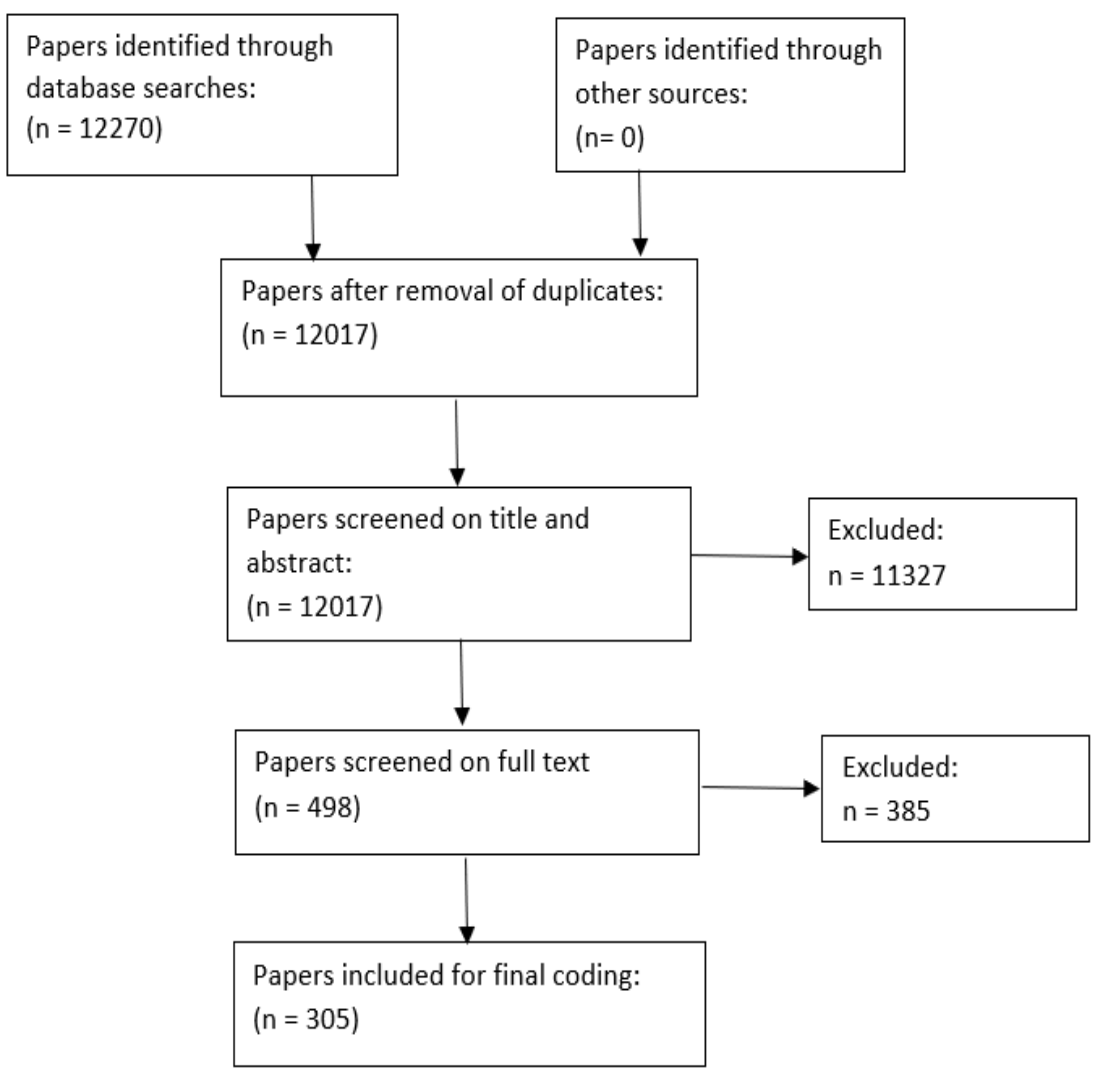

Figure 1: PRISMA diagram for the systematic review (adapted from Moher et al. 2009)

\section{Coding}

The intention of the systematic review was to present an overview of the global research activity around STEM MOOCs. The researchers therefore developed a coding system to reflect the activity. The coding included the author demographics, subject focus, learner levels (schools, undergraduate), and the aspect of the MOOC that was the focus of the paper. The coding scheme is shown in Table 3. 
Table 3: The coding scheme for the systematic review

\begin{tabular}{|l|l|}
\hline $\begin{array}{l}\text { Author } \\
\text { demographics }\end{array}$ & $\begin{array}{l}\text { Africa, Europe and UK, Asia, North America, South } \\
\text { America, Australia and New Zealand }\end{array}$ \\
\hline Subject focus & $\begin{array}{l}\text { Physics, Engineering, ICT and Programming, Astronomy, } \\
\text { Mathematics and Statistics, Robotics, STEM Generic, } \\
\text { Chemistry, Nanotechnology, Other }\end{array}$ \\
\hline Learner level & $\begin{array}{l}\text { School, undergraduates, postgraduates, working persons, } \\
\text { general public (no prerequisites), other, more than one } \\
\text { group of learners }\end{array}$ \\
\hline $\begin{array}{l}\text { Aspect of MOOC } \\
\text { that was focused on }\end{array}$ & $\begin{array}{l}\text { Design of MOOC, MOOC content, MOOC engagement, } \\
\text { completion/attrition, MOOC assessment, evaluation of } \\
\text { MOOC quality/success, future proposals for MOOCs, } \\
\text { technology, other }\end{array}$ \\
\hline
\end{tabular}

\section{Findings}

As indicated in the previous section, the systematic literature review focused on a highlevel understanding of STEM MOOCs in terms of author demographics, subject focus, learner level, and MOOC aspect that was focused on by the researchers. For this article, the literature pertaining to the selected subject focus of robotics, namely, engineering, physics, and programming and ICT are also presented as these are closely related to robotics.

\section{Programming and ICT, Engineering, Physics and Robotics - Subject Focus}

The relative presence of the literature for the subject focus code is presented. The subject focus code of the 305 papers in the study is highlighted.

From Figure 2 it may be noted that the most articles refer to programming and ICT MOOCs (146), whereas the least articles refer to robotics (7). This represents a percentage frequency of 48 per cent and 2 per cent. These frequencies are presented as percentages in Figure 3. 
STEM MOOC: Frequency Count of Subject Code $(n=305)$

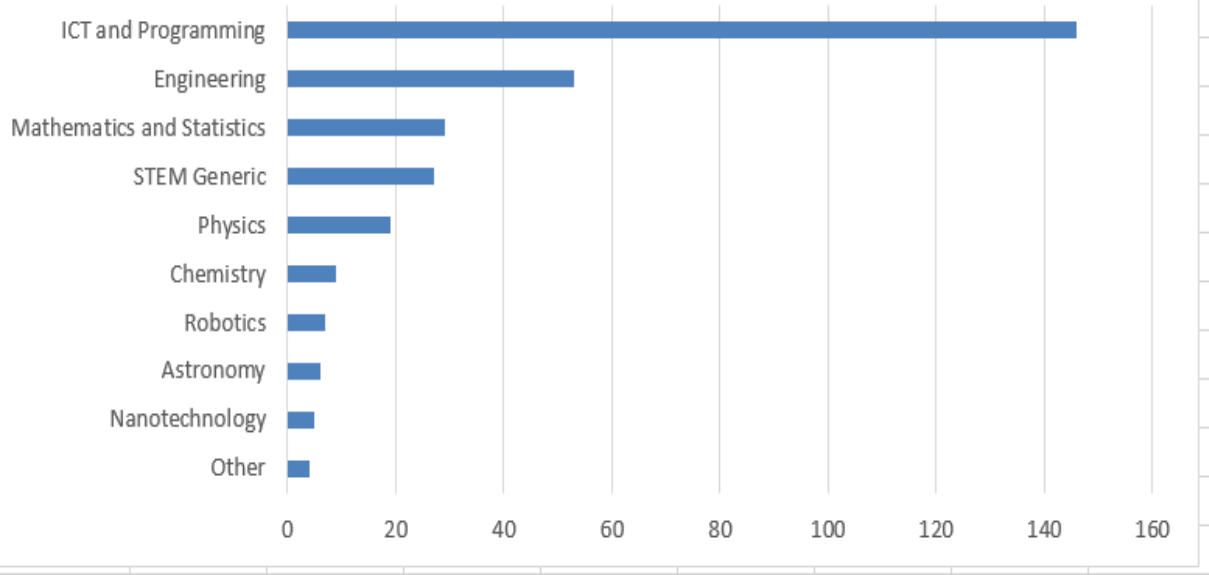

Figure 2: STEM MOOC: Frequency count of subject code $(n=305)$

STEM MOOC: \% Distribution of Subject Code ( $n=305)$

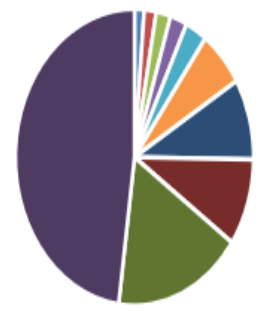

$\begin{array}{lll}\text { - Other } & \text { " Nanotechnology } & \text { "Astronomy } \\ \text { - Robotics } & \text { "Chemistry } & \text { "Physics } \\ \text { - STEM Generic } & \text { " Mathematics and Statistics } & \text { " Engineering } \\ \text { - ICT and Programming } & & \end{array}$

Figure 3: STEM MOOCs: Percentage distribution of subject code $(n=305)$

From Figures 2 and 3, it is noted that programming and ICT articles are in the majority $(48 \%)$, whereas the robotics articles are in the minority (2\%). The selected literature articles were coded on subject, focus, demographics of author and target audience.

\section{Robotics MOOCs - Author Demographics}

The authorship of the articles pertaining to robotics MOOCs is presented in Figure 4. 
In Figure 4, it is noted that most of the articles are authored in Europe and the UK (57\%), and the fewest of the articles are authored in Australia and New Zealand (14\%). However, of concern (or an opportunity) is that the literature review did not include any research pertaining to the use of robotics MOOCs in Africa.

\section{STEM MOOC Robotics - Author demographics $(n=7)$}

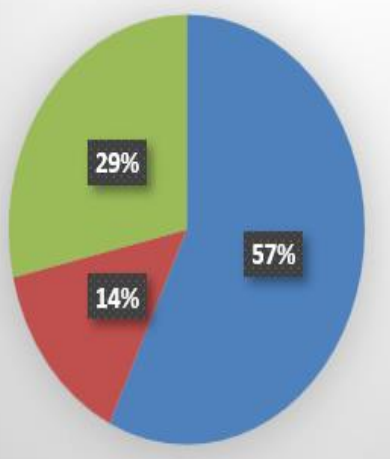

- Europe and UK

- Australia \& New Zealand

north America

Figure 4: STEM MOOC robotics research - Author demographics $(n=7)$

\section{Robotics MOOCs - Student Focus}

The student focus of the articles pertaining to robotics MOOCs is presented in Figure 5.

In Figure 5, it is noted that most of the robotics MOOCs focused on the public (43\%), which is one of the characteristics of MOOCs.

\section{STEM MOOC Robotics - Student focus $(n=7)$}

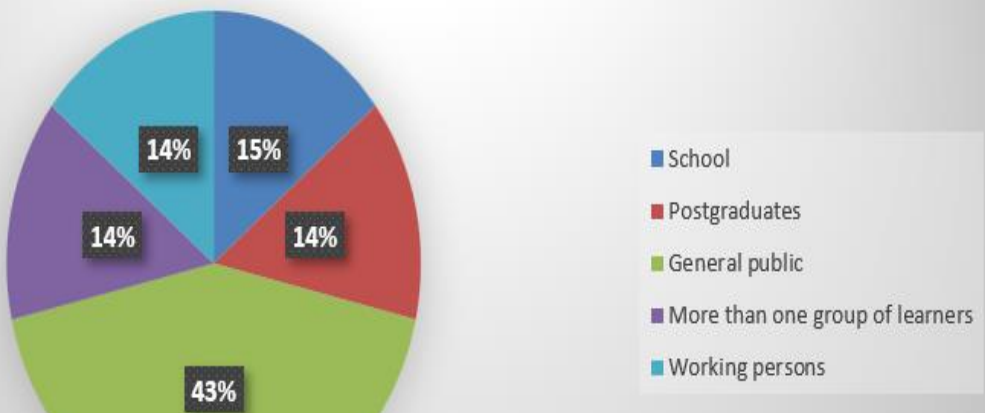

Figure 5: STEM MOOC robotics - Student focus $(n=7)$ 


\section{Robotics MOOCs - Research Focus}

The research focus of the articles pertaining to robotics MOOCs is presented in Figure 6.

In Figure 6, it is noted that most of the robotics MOOCs focused the design of the MOOC (72\%). Given the growing trend of MOOCs, it is in line with trends to develop the knowledge base of good design practice for robotics MOOCs. There is, however, clearly a need for more extensive research on MOOC engagement, as student throughput in MOOCs remains an issue.

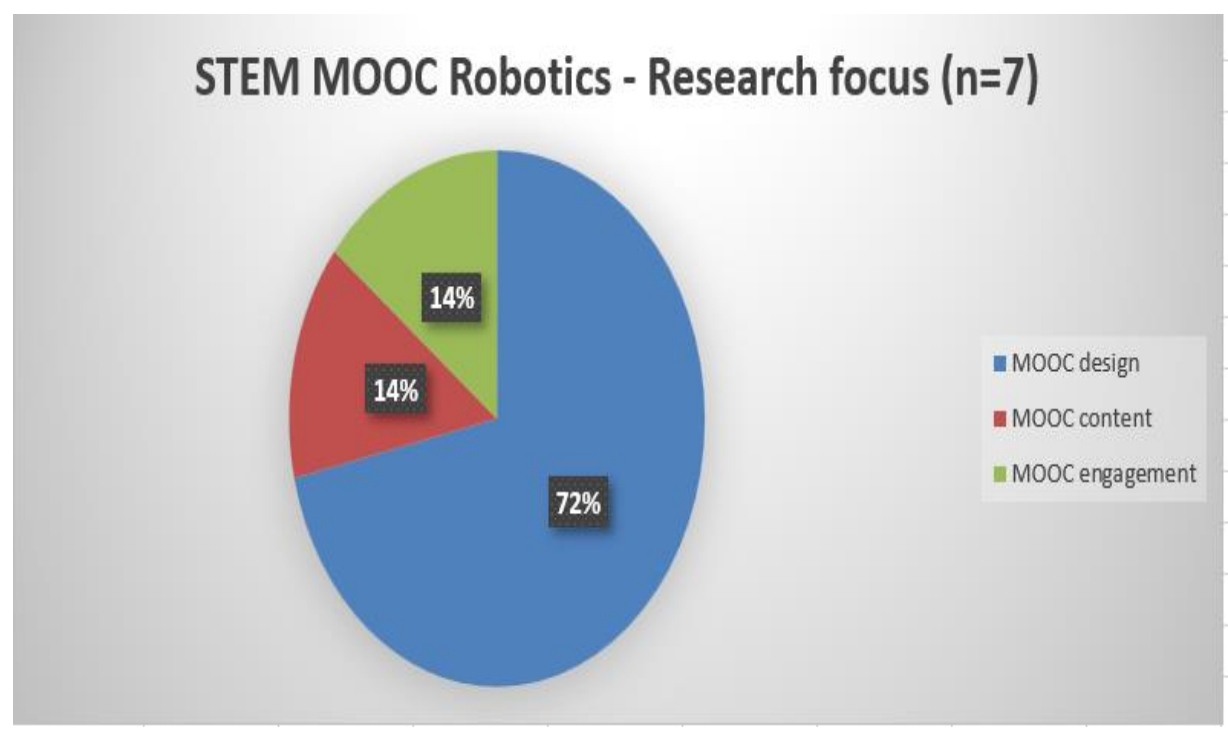

Figure 6: STEM MOOC robotics - Research focus $(n=7)$

\section{Conclusion}

From the findings of this systematic literature review, it may be concluded that there exists a role and place for STEM MOOCs, specifically in robotics in ODeL. MOOCs may provide a practical and sustainable solution to science engagement highlighted by the challenges experienced during the Covid-19 pandemic. There exists an opportunity to use STEM MOOCs to increase the access to robotics through science engagement, where the target audience may include all levels of the public, thus coaches (educators, mentors, and community leaders). The STEM MOOCs, to support the robotics teaching and learning, may include a focus on engineering at undergraduate level, a focus of programming for all levels and a focus of physics. The role and place of STEM MOOCs in the ODeL environment are as follows: 
- For the current students (undergraduate and postgraduate) in the ODeL institution, the STEM MOOCs provide free additional or enhanced learning for robotics content not included in the curriculum.

- For the public, including the coaches (educators, mentors, and community leaders), the STEM MOOCs develop robotics education and twenty-first century skills that are required.

- For the learners (the future students of the ODeL) that are in robotics teams, the STEM MOOCs provide an opportunity to engage with learning (specifically in robotics) before registration of formal qualifications in an ODeL institution of higher learning.

Not all students can embrace and register for a formal qualification that requires the completion of 30 modules over numerous years owing to time and fund constraints. The STEM MOOC provides an alternative learning path to an opportunity to access free learning and to continue lifelong learning. The opportunity for service of humanity thus urgently requires the development of robotics education for all coaches (educators, mentors, and community leaders). From the literature, it was noted that MOOCs are limited to European languages (Pozzi, Prattichizzo, and Malvezzi 2021). The role and place of robotics MOOCs at Unisa, the ODeL "in service of humanity in Africa", are therefore to redress the need to Africanise the MOOC content in the ODeL environment.

\section{References}

Adam, Taskeen. 2020. “Open Educational Practices of MOOC Designers: Embodiment and Epistemic Location.” Distance Education 41 (2): 171-85. https://doi.org/10.1080/01587919.2020.1757405.

Aiken, John M., Lin Shih-Yin, Scott S. Douglas, Edwin F. Greco, Brian D. Thoms, Michael F. Schatz, and Marcos D. Caballero. 2014. "The Initial State of Students Taking an Introductory Physics MOOC.” ArXiv 53-56. https://doi.org/10.1119/perc.2013.pr.001.

Alimisis, Dimitris. 2019. “Teacher Training in Educational Robotics: The ROBOESL Project Paradigm.” Technology, Knowledge and Learning 24 (2): 279-90. https://doi.org/10.1007/s10758-018-9357-0.

Anwar, Saira, Nicholas Alexander Bascou, Muhsin Menekse, and Asefeh Kardgar. 2019. “A Systematic Review of Studies on Educational Robotics." Journal of Pre-College Engineering Education Research 9 (2): 19-42. https://doi.org/10.7771/2157-9288.1223.

Balint, Trevor A., Raluca Teodorescu, Kimberly Colvin, Youn-Jeng Choi, and David Pritchard. 2017. "Physics Instructional Resource Usage by High-, Medium-, and Low-Skilled MOOC Students.” Physics Teacher 55 (4): 222-25. https://doi.org/10.1119/1.4978719. 
Beyers, R. N., and L. van der Merwe. 2017. "Initiating a Pipeline for the Computer Industry: Using Scratch and LEGO Robotics.” In 2017 Conference on Information Communication Technology and Society (ICTAS), 1-7. https://doi.org/10.1109/ICTAS.2017.7920646.

Canonne, Jean-Charles, Jean-Paul Becar, Aurel Fratu, and Mariana Fratu. 2015. "A Robotics Experience with MOOC.” In Iceri2015: 8Th International Conference of Education, Research and Innovation, 6420-25.

De la Croix, J., and M. Egerstedt. 2014. "Flipping the Controls Classroom around a MOOC." In 2014 American Control Conference. https://doi.org/10.1109/ACC.2014.6858682.

Gong, Lilin, Yang Liu, and Wei Zhao. 2019. "Dynamics of Emotional States and Their Relationship with Learning Outcomes during Learning Python with MOOC.” ACM International Conference Proceeding Series Part F1483: 71-76. https://doi.org/10.1145/3323771.3323821.

Gouws, P., H. H. Lotriet, and M. G. Katumba. 2021. "An Exploratory Analysis of the Potential for the Use of MOOCs in Support of STEM Engagement." STEM Community of Practice Conference, 20-22 July 2021.

Johnson, Jeffrey. 2003. "Children, Robotics and Education.” In The International Symposium on Artificial Life and Robotics.

Khalil, Mohammad, and Martin Ebner. 2015. “A STEM MOOC for School Children - What does Learning Analytics Tell Us?” In Proceedings of 2015 International Conference on Interactive Collaborative Learning, ICL 2015, 1217-21. IEEE.

https://doi.org/10.1109/ICL.2015.7318212.

Mitchell, R. J. 2018. “Using 'Begin Robotics' in Undergraduate Teaching.” In 2018 UKACC 12th International Conference on Control (CONTROL). Sheffield.

Moher, David, Alessandro Liberati, Jennifer Tetzlaff, Douglas G. Altman, Doug Altman, Gerd Antes, David Atkins, et al. 2009. "Preferred Reporting Items for Systematic Reviews and Meta-Analyses: The PRISMA Statement.” PLoS Medicine 6 (7). https://doi.org/10.1371/journal.pmed.1000097.

Oyo, Benedict, and Billy Mathias Kalema. 2020. "Massive Open Online Courses for Africa by Africa." International Review of Research in Open and Distributed Learning 15 (6). https://doi.org/10.19173/irrodl.v15i6.1889.

Philip, R., and E. Greener. 2016. "Robotics MOOC s Evaluation Report 2015.” Brisbane: Queensland University of Technology. https://eprints.qut.edu.au/103552/.

Pisarov, Jelena, and Gyula Mester. 2019. "Programming the Mbot Robot in School." In Proceedings of the International Conference and Workshop Mechatronics in Practice and Education, MechEdu, 45-48. https://www.researchgate.net/profile/JelenaPisarov/publication/337926235_Programming_the_mBot_Robot_in_School/links/5f6003d b299bf1d43c04e354/Programming-the-mBot-Robot-in-School.pdf. 
Pozzi, M., D. Prattichizzo, and M. Malvezzi. 2021. “Accessible Educational Resources for Teaching and Learning Robotics." Robotics 10 (38): 1-21. https://doi.org/https://doi.org/10.3390/robotics10010038.

Sahay, Atul, Smita Gholkar, and Kavi Arya. 2019. "Selection-Based Question Answering of an MOOC." ArXiv, 1-5.

Schwab, K. 2017. The Fourth Industrial Revolution. Currency.

Shailaja, J., and Sandhya Prathikantham. 2018. "Survey on Understanding the Implications of MOOCs in Engineering Education." Journal of Engineering Education Transformations 2018 (Special Issue). https://doi.org/10.16920/jeet/2018/v0i0/120929.

Shannon, Li-Jen. 2015. "BEST Robotics Practices." International Journal of Information and Education Technology 5 (3): 179-83. https://doi.org/10.7763/ijiet.2015.v5.498.

Tømte, Cathrine Edelhard. 2019. "MOOCs in Teacher Education: Institutional and Pedagogical Change?" European Journal of Teacher Education 42 (1): 65-81. https://doi.org/10.1080/02619768.2018.1529752. 